\title{
Correction to: Effective adsorption of nutrients from simulated domestic sewage by modified maifanite
}

\author{
Zisen Liu ${ }^{1}$ Yilingyun Zou ${ }^{1,2} \cdot$ Yunli Liu ${ }^{1,2} \cdot$ Feng Luo $^{3} \cdot$ Rou Wang $^{1,2} \cdot$ Zhenbin Wu $^{1,4} \cdot$ Yi Zhang $^{1,2}$ (D) \\ Published online: 3 January 2022 \\ ○) Springer-Verlag GmbH Germany, part of Springer Nature 2021
}

\section{Correction to: Environmental Science and Pollution Research https://doi.org/10.1007/s11356-021-17661-6}

Yilingyun Zou is co-First author.

The Original article has been corrected.

Publisher's note Springer Nature remains neutral with regard to jurisdictional claims in published maps and institutional affiliations.

The original article can be found online at https://doi.org/10.1007/ s11356-021-17661-6.

Yi Zhang

zhangyi@ihb.ac.cn

1 State Key Laboratory of Freshwater Ecology and Biotechnology, Institute of Hydrobiology, Chinese Academy of Sciences, 7\# Donghu South Road, Wuhan 430072, China

2 University of Chinese Academy of Sciences, Beijing 100049, China

3 School of Resource \& Environmental Engineering, Wuhan University of Technology, Wuhan 430070, China

4 School of Environmental Studies, China University of Geosciences, Wuhan 430074, China 